\title{
SOBREVOANDO ANALITICAMENTE AS TEORIAS DA ADMINISTRAÇÃO
}

\author{
Flying Over Analytically Management Theories
}

Recebido em 09.10.09 / Aceito em 11.02.10

Luiz Alex Silva Saraiva ${ }^{1}$

\section{Resumo}

A orientação predominantemente descritiva da maior parte das publicações a respeito da Teoria da Administração não resiste, em diversos aspectos, a um exercício analítico mais aprofundado. Via de regra, a descrição é enfatizada em detrimento da análise, o que limita uma perspectiva mais ampla de aprendizado, mas também estimula reflexões teóricas renovadas. O objetivo neste ensaio é fazer um sobrevoo das teorias de Administração sob um prisma crítico, de maneira a contribuir para um debate mais amplo sobre a Ciência da Administração.

Palavras-chave: Teorias da Administração; História da Administração; Escolas da Administração; Síntese; Análise Crítica.

\section{Abstract}

Descriptive orientation of most part of publications on Management Theories do not resist to a deeper theoretical critics. Usually, description is emphasized while analysis is despited, what brings interesting opportunities to reflect theoretically with new point of views. In this essay, we fly over management theories on a critical point of view to contribute to a wider debate about management science.

Keywords: Management Theory; Management History; Management Schools; Synthesis; Critical Analysis.

\footnotetext{
1 Doutorando e Mestre em Administração pelo Centro de Pós-Graduação e Pesquisas em Administração da Universidade Federal de Minas Gerais. Pesquisador do Núcleo de Estudos Organizacionais e Simbolismo (NEOS) da Universidade Federal de Minas Gerais e do Núcleo de Estudos Organizacionais e Tecnologias de Gestão (NEOTEG) da Universidade Salvador. Vice-Diretor da Faculdade de Ciências Administrativas e Contábeis da Fundação Comunitária de Ensino Superior de Itabira (FUNCESI), onde também é Coordenador do curso de Administração e do MBA em Gestão Empresarial. E-mail: lassaraiva@uol.com.br.
} 


\section{Introdução}

Assiste-se a uma era na qual o capitalismo posa como único e virtual vencedor, em que o neoliberalismo se espraia (FORRESTER, 1997), seja em termos de conexão financeira internacional, seja mediante uma retórica fatalista e baseada em um futuro sombrio para as formas alternativas de produção e organização societárias. Especialmente no nível ideológico, apresenta-se, sem cerimônias, o pensamento único, que desafia, altivamente, quaisquer alternativas consistentes.

Tal sentimento é reiterado pela mídia (CHOMSKI, 2002) e confirmado de forma impotente por boa parte da população, que assiste ao sucateamento do Estado - cada vez com mais dificuldades de oferecer condições efetivas de cidadania aos indivíduos - e ao aumento brutal na quantidade de desempregados, pensando-se indefesa e vítima de um sistema que ela própria criou (FORRESTER, 2001).

Em particular, no movediço terreno da Administração, as manifestações em prol da flexibilidade radical e necessidade de adaptação a condições incertas se materializaram em uma disciplina que se contenta, na maior parte dos casos, em disseminar um pensamento conformista e acrítico em detrimento de um raciocínio analítico mais amplo, próprio do conhecimento científico (FOURNIER; GREY, 2000). Os embates, quando existem, não satisfazem às expectativas mínimas de conflito e renovação de conteúdo porque se prefere adotar pontos de vista já balizados pelo tempo, por serem argumentos de autoridades (DEMO, 1987).

A formação do senso crítico a partir das salas de aula também se vê prejudicada à medida que os próprios docentes não foram preparados dentro de um paradigma crítico-reflexivo, o que resulta em sistemas de ensino e aprendizado mais voltados para a repetição do que para a inovação. Além disso, uma tradição pedagógica centrada no docente e não no aluno, outorga, historicamente, àquele o dever de ensinar e desobriga este a buscar o aprendizado por conta própria. Some-se a isso a proliferação dos cursos de graduação em Administração, os problemas estruturais ligados à educação e o baixo número de leitores no Brasil e o quadro tende a ficar mais completo para explicar por que falta uma postura mais crítica nessa área.

Quanto mais se amplificam os desdobramentos do conhecimento proveniente de manuais, que tudo sabem, tudo prescrevem e tudo preveem - um porto seguro para muitos docentes - mais é adiada a emancipação analítica da área, que permanece limitada nas iniciativas de dissecar as propostas, explícitas ou implícitas, encerradas nas Teorias de Administração. Prevalece, assim, um notável consenso ortodoxo (FISCHER, 2001) que, muitas vezes, se faz mais pela falta de argumentos do que pela concordância de conteúdo.

As questões levantadas até aqui integram o objetivo deste ensaio, que é explorar analiticamente algumas das possibilidades das Teorias da Administração, em uma espécie de sobrevoo. Propõe-se um esforço associado de síntese e análise a fim de que as propostas sejam interpeladas à luz das dimensões existentes nas organizações contemporâneas. Espera-se, assim, que o papel da ciência seja cumprido no que tange ao questionamento de verdades absolutas com vistas ao esclarecimento e aprofundamento de questões.

Para tanto, este ensaio se encontra estruturado da seguinte maneira. Inicialmente são discutidos os aspectos referentes ao primeiro período da administração, chamado metaforicamente de "mecanização". Na segunda seção, a perspectiva humanista é discutida em detalhes. Em seguida, a racionalidade proposta pela abordagem burocrática é tratada. A teoria dos sistemas é discutida a seguir em seus principais pontos, sendo sucedida por uma análise sobre a visão da teoria contingencial. Posteriormente, as teorias econômicas sobre a organização são dissecadas. Por fim, encerra-se o capítulo mediante uma análise da teoria da administração e do seu contexto. 


\section{Os primórdios da Administração - a mecanização}

Os primórdios da atividade industrial - especialmente na Inglaterra e nos Estados Unidos, países que lideraram o processo de desenvolvimento industrial - evidenciaram a necessidade de organização em um sentido mais amplo. Um dos indicativos era o fato de que, não obstante os operários tivessem uma extensa carga de trabalho, não existiam meios objetivos de controlar seus métodos ou volume de produção. Neste contexto, surgiram alguns pioneiros da então nascente ciência da Administração, professando ideias revolucionárias que começaram a imprimir características bem definidas do que nos dias atuais convencionou-se denominar de teoria clássica da administração.

Frederick Winslow Taylor, engenheiro norte-americano, partindo do pressuposto (antagônico ao marxismo) de que patrões e empregados possuem interesses comuns, lançou as bases da "administração científica", que se baseia nos seguintes pontos: "primeiro, a cuidadosa seleção do trabalhador; segundo e terceiro, o método de instruí-lo, primeiramente, e depois treiná-lo a trabalhar de acordo com o sistema de administração científica" (TAYLOR, 1990, p. 47), com o objetivo fundamental de garantir a máxima prosperidade ao patrão e ao empregado.

Com alguns posicionamentos semelhantes aos de Augusto Comte, um filósofo positivista que acreditava na existência de leis universais que regulariam a realidade de forma natural e harmônica, Taylor (1990, p. 52) acreditava na existência de "uma lei definida e simples, que permitia determinar o trabalho quotidiano dum operário de primeira ordem". Ele passou a perseguir de forma sistemática este princípio fundamental, ao qual denominou de 'lei da fadiga', que determinaria, baseado em estudos fisiológicos de tempos e movimentos, a quantidade de esforço 'suportável' para um dia produtivo de trabalho.

O engenheiro francês Henri Fayol, baseado em sua experiência como administrador de vários empreendimentos, com uma abordagem um pouco diferenciada da taylorista, partiu do princípio de que a função administrativa tem por instrumento o corpo social da organização. Para preservar seu adequado funcionamento, a empresa deveria observar atentamente certo número de princípios, como, por exemplo, a divisão do trabalho, as noções de autoridade e de responsabilidade, as unidades de comando e centralização. Fayol (1990) procurou analisar a organização nos seus aspectos administrativos, buscando compreender e explicar o funcionamento, ou melhor, os fatores ligados ao desempenho adequado das diversas partes da empresa mediante um sistema organizado de princípios que definiriam e harmonizariam as funções da organização.

Outro personagem desta fase foi o empresário americano Henry Ford. Fundador da Ford Motors Company, que serviu como uma espécie de 'laboratório' para a aplicação de seus revolucionários princípios de produção, acreditava que a racionalização do trabalho em larga escala deveria ser amplamente adotada para garantir tanto um significativo aumento da produção quanto uma acentuada "redução no custo médio de cada veículo produzido na linha de montagem" (BEYNON 1995, p. 41). O controle, inicialmente focado sobre os métodos utilizados pelos operários na execução de suas tarefas e, posteriormente, sobre suas vidas particulares era fundamental e poderia ser considerado como característica intrínseca do modo 'Ford' de administrar.

Não obstante ter sido um pioneiro sob vários aspectos, a maneira fordista de administrar não foi a única vigente na época. A General Motors, fundada em 1908 e consolidada com o passar do tempo com a incorporação de várias outras pequenas companhias fornecedoras, depois de apresentar sérios problemas concernentes à sua complexa e confusa estrutura administrativa, 
iniciou, em 1920, um amplo processo de reorganização. Conforme Sloan (1965, p. 66), não era possível "controlar o ambiente ou predizer-lhe as mudanças com precisão, mas estava nas nossas mãos procurar a flexibilidade que permitisse sobreviver à flutuação dos negócios". Tais esforços resultaram em um documento interno - o 'estudo de organização' - destinado, inicialmente, a propor soluções para as consequências do crescimento desordenado da empresa após a Primeira Guerra Mundial e que veio a tornar-se a base das normas administrativas da empresa, sendo, de acordo com Sloan (1965, p.69), “a expressão de princípios fundamentais de descentralização que regem a organização".

Nos primórdios da Administração, pode-se perceber que a ideia do aumento de produtividade global marcou sensivelmente as distintas iniciativas da época, tanto por meio de um plano estratégico, quanto pela adoção de normas rígidas de controle da produção, pela instituição de mecanismos reguladores da organização administrativa interna ou por um avançado sistema de especialização funcional. No entanto, tal produtividade não foi conseguida sem sacrifícios; pelo contrário, ao serem estabelecidos processos efetivos de controle, nos quais pela primeira vez o "pensar" (planejamento das atividades) e o "fazer" (execução das tarefas) foram concebidos como processos distintos, a mão de obra passou a vivenciar intensamente a maisvalia marxista: uma série de medidas integradas com o objetivo maior de desenvolver continuamente o processo produtivo, mesmo que viesse a trazer consequências devastadoras para o trabalhador (SARAIVA; PROVINCIALI, 2002).

O processo de "mecanização" da produção (no sentido de transformar inclusive os operários em peças eficientes e eficazes da grande engrenagem industrial), se por um lado lançou as bases do moderno sentido de capitalismo e, como consequência, da Administração como ciência, sob outro aspecto trouxe um enorme elenco de implicações - nem sempre positivas - para a força de trabalho, consequências estas que merecem ser amplamente pesquisadas e discutidas com vistas a melhor compreensão do capitalismo, suas características e seus inter-relacionamentos com o homem e as organizações inseridas em seu contexto (SARAIVA; SILVEIRA, 2007).

\section{Uma alternativa ao mecanicismo - a perspectiva humanista}

Os desdobramentos da Teoria Clássica da Administração alimentaram de ideias os antagonistas desse modelo, o que culminou com a fundação da Escola das Relações Humanas na década de trinta. Concebida como uma reação à perspectiva mecanicista, esta abordagem, que teve em Elton Mayo seu maior expoente, partiu do princípio de que os incentivos de pagamento poderiam até ter alguma influência sobre os resultados, mas esta não seria importante, pois estes são influenciados principalmente pelas transformações na atitude mental dos trabalhadores (MAYO, 1959, p. 76).

Esta escola, influenciada pelo behaviorismo norte-americano, passou a querer comprovar, por uma série de experiências, das quais a mais significativa foi a de Hawthorne, que o meio ambiente, estando aí inclusas especialmente as variáveis sociais, tinha uma ação preponderante sobre o desempenho do operário. Entre outras conclusões, identificou que a produção começou a se elevar somente quando os operários, sob orientação interessada de supervisores habilidosos, passaram a constituir um grupo coeso (BENDIX; FISHER, 1991, p.125). Registrada a existência da organização informal, que se refere aos valores e comportamentos derivados naturalmente da interação do grupo de trabalho, deduziu-se que a vida em grupo resulta, para o indivíduo, em fonte de satisfação social e de estabilidade emocional, diminuindo seus erros e o absenteísmo (MOUZELIS, 1975, p. 110). 
O conceito de organização informal levou os teóricos da Escola das Relações Humanas à noção de sistema social, um todo de partes interdependentes, no qual a mudança sofrida em uma das partes acarreta modificações nas situações de todos os demais, o que a levou à conclusão de que a organização só pode ser compreendida se observada em seu conjunto. A constatação de que o grupo desenvolve um sentido de participação nas decisões e que se transforma em uma unidade social foi, sem sombra de dúvida, a maior contribuição desta abordagem para a Administração, pois se acabava com a imagem distorcida do grupo como um aglomerado de pessoas disposto a ser uma eterna fonte de problemas para a empresa. O grupo passa a ser visto, mais do que uma simples reunião de pessoas, como reflexo de uma complexa rede de interrelacionamentos.

Na experiência de Hawthorne, as observações sobre as condições materiais de trabalho tinham maior valor do que as observações sobre pessoas, o que confirma a sua predisposição para que fossem 'adaptados' os métodos, mas sem contrapartida em relação à organização humana (MAYO, 1959, p. 98). Os humanistas sustentavam que a insistência em uma lógica de produção puramente econômica interfere no desenvolvimento do código social, gerando um sentimento de frustração humana, e propõem uma abordagem claramente voltada para o problema da produtividade industrial. Isto é comprovado pelo fato de que, mesmo tendo sido constatada nesta experiência que a redução no nível de supervisão resultava em maiores níveis de produtividade, o controle continuava a ser utilizado disfarçadamente pela indústria, sob o pretexto de auxiliar a interpretação dos resultados e de efeitos psicológicos dos estudos (MAYO, 1959, p.76).

A crença ingênua de que um ambiente de trabalho mais livre de controles levaria a um aumento na produtividade industrial culminou com um estudo que, pouco se importando em beneficiar os operários, apenas buscava identificar os fatores relacionados ao aumento da sua produção, só que com um agravante: a adoção cínica do slogan 'as pessoas em primeiro lugar'. Ficou caracterizada a restrita base empírica da Escola de Relações Humanas, e seus esforços para encontrar este apoio aumentaram suas limitações, pois, apesar de criticar a abordagem clássica e seus pseudocientíficos estudos de fisiologia visando à maximização da produtividade, possui a mesma preocupação em torná-lo mais produtivo, com manifestações disfarçadas de controle.

Esta abordagem também foi criticada por ressaltar em demasia a harmonia em detrimento do conflito, consequência de sua ideologia pró-capitalista e da utilização de conceitos conservadores, com o intuito principal de manter a mão de obra satisfeita e alienada com paliativos organizacionais. Nota-se o quanto é estreita a sua abordagem quando ela ignora o caráter econômico da empresa moderna, que implica a existência de problemas específicos e em uma estrutura peculiar de poder, que traz em seu bojo inevitáveis conflitos sociais Além das críticas acima mencionadas, Mouzelis (1975, p. 122) aponta que o único defeito fundamental da Escola de Relações Humanas é o de ter tentado solucionar todos os grandes problemas organizacionais considerando unicamente o indivíduo e os pequenos grupos, ignorando a organização em seu conjunto, justo uma das primeiras contribuições da escola à análise das organizações. 


\section{A "racionalidade" e seus desajustes}

O contexto de indefinição que marcou a coexistência das práticas e pressupostos da Teoria Clássica e da Escola de Relações Humanas foi ideal para a propagação do conceito weberiano de administração racional - a burocracia - que viria a marcar indelevelmente a forma pela qual se encontram estruturadas as organizações contemporâneas. Partindo de um pressuposto diferente da concepção mecanicista da Teoria Clássica, e do 'humanismo' da Escola das Relações Humanas, a Teoria Burocrática da Administração, sistematizada inicialmente por Max Weber, baseou-se na noção de burocracia, um "tipo de poder ou dominação de caráter racional tendo em vista o atingimento eficiente de fins visados" (PRESTES MOTTA; BRESSER PEREIRA, 1984, p. 21).

Concentrando-se inicialmente nas formas de dominação, Weber (1982) identificou três tipos de dominação: a carismática, sem base racional e originada nos dotes especiais do líder, que justificam o poder a ele conferido por seus seguidores; a tradicional, que privilegia o caráter conservador dos usos e costumes vigentes e cujo poder pode ser repassado de geração a geração; e, por último, o tipo ideal de dominação, a burocrática, cuja legitimidade sustentase no cumprimento de normas legais racionalmente definidas e voltadas para a consecução de propósitos específicos.

O progresso da organização burocrática teria como razão decisiva sua superioridade técnica sobre qualquer outra forma de organização (GUERREIRO RAMOS, 1983, p.191-192). Esta superioridade, peculiar a este tipo de organização, baseia-se em três aspectos principais: um sistema de autoridade derivado de um conjunto de "normas racionais, escritas e exaustivas, tendo em vista os fins visados; segundo, caracteriza-se por uma hierarquia organizada de mando e subordinação mútua das autoridades; e, por fim, a burocracia é departamentalizada, de acordo com os objetivos a serem atingidos" (PRESTES MOTTA; BRESSER PEREIRA, 1984, p. 29-32).

A ênfase em normas escritas, se por um lado constituiu inegável avanço no sentido de proporcionar formas mais técnicas no ambiente de trabalho, por outro levou, disfuncionalmente, a um excesso de burocratização, que ocorre quando as normas e regulamentos internos deixam de ser meios de garantir o alcance eficiente de objetivos e passam a ser os fins da organização. Neste caso, todo o sistema tende a entrar em colapso, pois, sem a noção real dos resultados a serem atingidos, tende-se a perder a noção de eficácia organizacional.

A impessoalidade proveniente da obediência a normas escritas é, seguramente, um dos mais importantes elementos no processo de existência da burocracia, pois pressupõe que, mesmo com o falecimento ou demissão do ocupante de um determinado cargo, este "é substituído por outro, de qualificações técnicas semelhantes" (ETZIONI, 1967, p. 89). Tal premissa traduz não apenas a extrema racionalidade da abordagem burocrática, mas também certo grau de proximidade com a Teoria Clássica, pois o homem, nas duas perspectivas, representa apenas uma peça do sistema, sem vontade própria - ou com uma vontade que não interessa à organização que o emprega.

Uma das principais disfunções do pensamento burocrático é, contraditoriamente, um dos seus pontos-chave: a racionalidade. À medida que a burocracia torna-se "mais eficiente quando se desumaniza" (PRESTES MOTTA; BRESSER PEREIRA, 1984, p. 33), a busca incessante por um melhor desempenho mostra que "não são pessoas saudáveis e satisfeitas aquelas mais úteis e produtivas para o [...] sistema, e, sim, aquelas mais neuróticas e infelizes. Quanto mais alienado for o indivíduo, mais interessante ele se torna para o [...] sistema produtivo" (LIMA, 1988, p. 76). Por conseguinte, as mesmas normas que impõem um padrão 'racional' de trabalho 
tornam o sistema nocivo ao homem quando ignoram o caráter flexível do ambiente. O capitalismo vê-se, desta forma, amplamente favorecido com o desenvolvimento da burocracia, porque esta, ao basear em normas seu caráter dominador, propicia um campo fértil para a proliferação de diversas atividades - em particular as econômicas - com a garantia de que haverá uma mão de obra obediente e produtiva, ainda que alienada.

A organização burocrática caracteriza-se, como consequência, também como um instrumento político a serviço das classes dominantes, pois "o homem é controlado em alto grau pelas suas relações sociais com os instrumentos de produção" (MERTON, 1968, p. 273). Assim, a natureza da burocracia, relacionada à manutenção da mão de obra devidamente disciplinada por parâmetros reconhecidos e 'aceitos' no contexto organizacional, garante tanto formas exemplares de punição (para os que não seguem as regras estabelecidas), quanto de recompensa (aos que se 'adaptam' aos pressupostos burocráticos). Contudo, esta adaptação não é como um processo indolor; pelo contrário, indica, em maior ou menor grau, um estado gradativo de alienação do funcionário, que modifica seu comportamento para permanecer parte da organização.

Portanto, mais do que um simples instrumento de dominação, a burocracia desempenhou um papel relevante no que se poderia chamar de processo de 'docilização da mão de obra', à medida que propôs normas claras, e às quais todos deveriam subordinar seus interesses, sob pena de "não aceitação" no contexto social (punição). Desta forma, a leitura da abordagem weberiana a respeito da burocracia enfatiza não apenas pontos consistentes no contexto atual quanto alerta a sociedade em geral para a necessidade de adequada compreensão da natureza dos fenômenos organizacionais, pois um bom entendimento das particularidades das organizações burocratizadas é necessário não apenas como constructo teórico, mas como um meio efetivo de visualização da realidade vigente.

\section{Os sistemas e seus desdobramentos}

Nascida das concepções do biólogo Ludvig von Bertalanffy, a Teoria dos sistemas apresentou-se, desde o princípio, como uma espécie de "resposta" às concepções que não consideravam o ambiente extraorganizacional. Ele entendia que, uma vez que o caráter fundamental da coisa viva é sua organização, a investigação costumeira das diversas partes e processos em separado não podia fornecer uma explicação completa do fenômeno (PRESTES MOTTA; BRESSER PEREIRA, 1984, p. 203). Sua perspectiva disseminou-se rapidamente sob o conceito generalista de sistema, inserido, por sua vez, em outros sistemas, em ambientes maiores e mais complexos, em um contexto de ampla interdependência ambiental.

Não desprezando as Teorias Burocrática, Clássica e de Relações Humanas, Bertalanffy (1973, p. 58) sustenta que "os modos clássicos de pensar, porém, deixam de ter êxito no caso da interação de um número grande, mas limitado de elementos ou processos", indicando que, por suas próprias limitações, eles não fogem à definição de sistema fechado, pois ignoram - ou pelo menos tentam minimizar - a importância das variáveis ambientais na vida interna das organizações. A Teoria de Sistemas, de forma contrária, enfoca problemas de relações, estrutura e interdependência, e não atributos constantes dos objetos de estudo, enraizando sua perspectiva sobre o que foi denominado de 'sistema aberto'.

De acordo com Katz e Kahn (1970, p. 32), "as organizações sociais são flagrantemente sistemas abertos, porque o input de energias e a conversão do output em novo input de energia 
consistem de transações entre a organização e seu meio ambiente". Um sistema, portanto, é um conjunto de partes coordenadas para realizar um conjunto de atividades; os sistemas são constituídos por conjuntos de componentes que atuam juntos na execução do objetivo global do todo. O enfoque sistêmico é simplesmente um modo de pensar a respeito desses sistemas totais e seus componentes (CHURCHMAN, 1972, p. 27-28). Esta perspectiva, que observa o que está além das fronteiras organizacionais, fez com que as organizações criassem estruturas adaptáveis para gerar reações apropriadas às condições externas. Esta preocupação com o ambiente apresentou um significativo grau de evolução, a ponto de Churchman (1972, p. 237) colocar que "em certo sentido, é o cliente que 'decide' como o administrador deve comportar$\mathrm{se}^{\prime \prime}$.

A Teoria Geral dos Sistemas apresenta aspectos altamente relevantes para a Teoria da Administração: primeiro, "parece ser um importante avanço no sentido da síntese interdisciplinária e da educação integrada" (BERTALANFFY, 1973, p. 78); a seguir, a visão de que a organização não apenas está inserida no ambiente como dele depende representa um avanço significativo no estudo da Teoria da Administração, pois toca em um ponto talvez propositalmente deixado de lado pelos antecessores. Contudo, a Teoria dos Sistemas é passível de críticas, a começar pelo seu suposto caráter de universalidade.

Bertalanffy (1973, p. 55) propõe uma nova disciplina cujo "conteúdo é a formulação e derivação dos princípios válidos para os 'sistemas' em geral". Esta nova teoria seria útil por fornecer modelos a serem usados em diferentes campos e transferidos de uns para outros, salvaguardando, ao mesmo tempo, do perigo das analogias vagas, que, muitas vezes, prejudicaram o progresso nesses campos. Embora haja coerência na proposta, ela não vem acompanhada de uma substancial contribuição teórica à área organizacional, pois a afirmação de que praticamente tudo é um sistema caracteriza-se muito menos como uma contribuição consistente do que como um reducionismo inconsequente, no qual, talvez, pela falta de argumento invoquem-se variáveis teóricas não só de difícil mensuração como de complexa definição.

Outro ponto passível de crítica é a suposta universalização do conceito sistêmico; anteriormente outras tentativas já foram feitas no sentido de descobrir "leis" que seriam aplicáveis a todas as ciências, independente do seu grau de desenvolvimento ou de sua natureza intrínseca, como se pode observar na obra de Comte (1978), por exemplo. Nos dias atuais, tal proposta parece estar muito mais próxima à superficialidade prescritiva do que a uma teoria metodologicamente coerente, pois ao mesmo tempo em que acentua a necessidade de adequação organizacional ao ambiente (ênfase da influência externa definindo a organização), prega que a realidade deve se "adequar" à teoria proposta.

Não obstante estes pontos "nebulosos", a Teoria dos Sistemas representou um significativo avanço no campo organizacional ao mudar o foco de estudo para os fatores situados fora da organização, o que auxiliou o desenvolvimento de outras áreas ligadas à administração (como o marketing, por exemplo). Churchman (1972, p. 293) aponta seu aspecto mais positivo ao afirmar que "a ciência de nossa sociedade tem de ser considerada como um sistema sujeito à mudança", ao invés de um todo acabado e que deve ser seguido "cegamente" pelos membros da organização, pois isto prejudica não apenas o seu desenvolvimento enquanto indivíduos, mas também, em longo prazo, o próprio futuro organizacional. 


\section{As múltiplas faces da visão contingencial}

Com origem na Teoria dos Sistemas, a Abordagem Contingencial apresenta como avanços os fatos de não apenas considerar a importância dos aspectos ambientais na vida organizacional, como também que não há um modo único de administrar, uma vez que a organização encontrase sujeita a contextos diferenciados, o que exige posturas e ações diferentes. Perrow (1991) salienta que embora existam estudos de diversas áreas para a compreensão da dinâmica organizacional e seus elementos, as conclusões eram semelhantes, principalmente com relação à constatação de que não existe uma melhor forma de conduzir uma organização.

Em um estudo sobre o relacionamento entre os princípios da empresa e o sucesso empresarial, Joan Woodward sustenta uma significativa ligação entre tecnologia e estrutura social. Na sua visão, o fato de "as características organizacionais, a tecnologia e o sucesso estarem ligados desta maneira sugere não apenas que o sistema de produção era uma variável importante na determinação da estrutura organizacional, mas também que uma forma particular de organização era mais apropriada para cada sistema de produção" (WOODWARD, 1977, p. 77).

Lawrence e Lorsch (1973, p. 20), por sua vez, salientam que a instabilidade ambiental à qual as organizações estão sujeitas constitui-se um fator de preocupação, de forma que é interessante conceber a empresa como um sistema aberto, no qual os comportamentos dos membros são inter-relacionados e interdependentes da organização formal, das tarefas a serem executadas, das personalidades de outros indivíduos e das regras não escritas relativas ao adequado comportamento de um membro. Esta interdependência organizacional leva às necessidades de diferenciação - para o adequado funcionamento das partes em separado - e de integração, a fim de que o sistema como um todo seja viável. Contudo, a integração não é alcançada de forma automática; para que se realize de fato, os conflitos precisam ser resolvidos. Lawrence e Lorsch (1973) colocam que, em ambientes mais estáveis, a solução dos impasses e a integração nos níveis superiores poderiam ocorrer por meio da hierarquia administrativa; já nos menos estáveis, a solução de conflitos e a realização da integração teriam de ocorrer nos níveis mais baixos da hierarquia.

O que importa é considerar que condições externas diversas podem exigir diferentes características organizacionais e padrões de comportamento no interior da empresa; ela deve ser estruturada, portanto, de maneira a proporcionar a seus membros a oportunidade de fazer bem seu trabalho, de modo que eles possam tratar de modo realista e eficiente as tarefas de que são incumbidos.

Perrow (1972) sustenta que a sobrevivência organizacional depende não apenas de assuntos materiais, mas também da aceitação do produto e dos métodos de operação pelo ambiente da organização. Neste sentido, são corretas as visões de Weber e Schumpeter, que "encaravam as grandes organizações como oriundas de condições sociais e culturais em transformação e, como elementos capazes de, por sua vez, mudar também estas mesmas condições, à medida que se expandiam" (PERROW, 1972, p. 125). O ponto central da argumentação de Perrow (1972) é que as organizações procuram modos de reduzir a insegurança ambiental introduzida pela concorrência: cada instituição torna-se profundamente ligada às suas técnicas imperfeitas, defendendo-as tanto mais, quanto menos eficazes elas se mostrarem e sem base racional para provar a inferioridade das técnicas dos concorrentes.

Com uma visão histórica que procura identificar até que ponto a estrutura organizacional é definida pelas decisões estratégicas, (CHANDLER, 1976, p. 2) considera necessária a existência de diversas formas organizacionais como meio de atender a diferentes expectativas ambientais.

Rev. Adm. UFSM, Santa Maria, v. 3, n.1, p. 26-40, jan./abr. 2010 
Segundo suas próprias palavras, "historicamente, administradores raramente têm mudado sua rotina diária e suas posições de poder, exceto sob forte pressão". Nos diferentes formatos organizacionais, entretanto, Chandler (1976, p. 11) afirma a existência de a formulação de políticas e procedimentos de caráter estratégico ou tático. Segundo suas palavras, "decisões estratégicas são concentradas durante o longo tempo de vida da organização. Decisões táticas objetivam mais o dia-a-dia de atividades necessárias para operações eficientes e bem-sucedidas". Mas, independente de sua natureza, as decisões requerem implementação, o que, normalmente, demanda recursos que somente a alta administração pode providenciar.

Sendo um 'aperfeiçoamento' da Teoria dos Sistemas, a Abordagem Contingencial, embora tenha trazido significativos avanços à área organizacional, principalmente por introduzir a noção de que não existe the best way de executar uma tarefa, e que a organização não é apenas influenciada, mas também tem papel ativo no relacionamento com o ambiente que a circunda, também traz consigo alguns dos defeitos daquela visão.

Ao encarar a organização como uma estrutura adaptável, sujeita às demandas ambientais (ou contingências), a Abordagem Contingencial corre o risco do relativismo, pois embora seja necessário um caráter de flexibilização, parece não existir um 'norte'; tudo depende do ambiente e de como ele vai definir a contribuição da organização. Apresenta-se como uma simplificação excessiva do multifacetado contexto organizacional, especialmente porque nem sempre o planejamento da organização pode responder de forma plena à demanda, em virtude da complexidade dos fatores envolvidos que precisam ser levados em consideração.

A sujeição ao contexto externo parece ser um paradoxo desta abordagem: se por um lado perceber as limitações da organização formal é vantajoso; por outro, a sujeição 'absoluta' às suas peculiaridades parece muito mais ser um ponto problemático do que desejável: pois se perderia a noção de racionalidade organizacional intrínseca, pois as regras não teriam razão de existir, nem como procedimento formal, a menos que tivessem relação direta com o que o ambiente determina. Além deste fato, não parece haver limites claros sobre onde terminam os limites organizacionais e onde se inicia o ambiente.

Assim, a Abordagem Contingencial, embora tenha avançado em relação à teoria dos sistemas, não conseguiu desvencilhar-se de suas mazelas, tendo sido produtiva especialmente pelo caráter interdisciplinar que marcou seu surgimento, mas, infelizmente, restrita com relação à visão organizacional de natureza administrativa, o que justificou uma aproximação das teorias econômicas em um momento seguinte.

\section{Teoria da firma e economia dos custos de transação}

As perspectivas organizacionais, amparadas em um contexto mais competitivo, necessitavam de uma abordagem que levasse em consideração não apenas o ambiente exterior à organização, mas, especificamente, operacionalizasse a forma de relacionamento entre este elemento e a organização. Neste sentido, novas perspectivas de análise apresentam-se não apenas como alternativas viáveis, mas como 'saídas' para a análise de um contexto com novas ferramentas teóricas.

O mercado, mais do que apenas um ambiente externo à organização, passou a ser tratado como um elemento definidor das novas formas organizacionais: a organização, desta maneira, não se encontraria mais simplesmente sujeita aos 'humores' dos superiores hierárquicos, pois agora, como um todo, se presta ao julgamento do mercado, entendido aqui como os 
acionistas, que possuem 'partes' da empresa, e que, em última instância, são seus verdadeiros proprietários à medida que financiam suas atividades. Nessa nova perspectiva de análise, o mercado "pode muito bem constituir a mais viável e eficiente das formas até aqui planejadas para a consecução da produção em massa, para a distribuição de bens e serviços e para a organização de determinados tipos de sistemas sociais de natureza econômica" (GUERREIRO RAMOS, 1981, p.195-196). Para isso, entretanto, é preciso delimitar suas atribuições, o que envolve a formulação e implementação de novos critérios e políticas de alocação no contexto de nações e entre elas, pois o Estado se torna um articulador de sistemas sociais, cuja missão é garantir que os mesmos se complementem de forma funcional.

No contexto específico da organização, Chandler (1990) destaca que das muitas recentes mudanças no desenvolvimento da moderna empresa industrial, seis não têm antecedentes históricos, como a adaptação organizacional a uma nova estratégia de crescimento; a separação da alta gerência corporativa da gerência média nas divisões de operação; o contínuo desmembramento de unidades de operação; a compra e venda de corporações como um negócio distinto do seu próprio ramo de atividades; o desenvolvimento de um know how gerencial para lidar com portfólio em mercados de capital; e a evolução destes mercados de capital no surgimento do termo "mercado para o controle corporativo. A nova realidade ambiental, portanto, impõe às organizações e, principalmente, à ciência, novas posturas de análise. Neste sentido, "podemos afirmar que se faz necessária uma revisão crítico-reflexiva das teorias organizacionais, para que sejam permeadas as contradições entre irracionalismos e racionalismos, tão presentes da dinâmica organizacional" (CARNEIRO, 1995, p. 68). Isso traria a substituição das práticas imediatistas por novas formas organizacionais, com o intuito de possibilitar a eficiente realização do trabalho cooperativo entre os diversos atores da organização.

As Teorias Econômicas da Organização se apresentam como uma das possibilidades de compreensão do multifacetado universo organizacional. Basicamente são modelos econômicos baseados nos indivíduos, mais que nas organizações, e no interesse competitivo entre os indivíduos. Nesta visão, a atividade econômica se reduz a uma série de contratos: a empresa é pouco mais do que contratos bilaterais, pois os economistas veem a vida com um caráter contratual a assim analisam as organizações (PERROW, 1991, p. 272).

A Teoria da Firma, a primeira dessas abordagens, não tem um problema claro para solucionar, pois parece refletir uma preocupação pela aplicação dos pressupostos econômicos para explicar os contratos e, deste modo, as organizações. Supõe que a vida social não é outra coisa senão uma série de contratos. A análise desta teoria é particularmente interessante não apenas porque sua popularidade é ascendente, mas também porque estuda as condições de conduta egocêntrica em vez de heterocêntrica: a conduta egocêntrica desta visão não é a essência das organizações, e a Teoria da Administração tem acertado ao tratar principalmente das questões estruturais; mas o interesse pessoal é um problema digno de ser investigado porque é uma propriedade fixa, e não variável, das organizações (PERROW, 1991, p. 283)

A Economia dos Custos de Transação (ECT), outra abordagem econômica, sustenta que as grandes organizações representam o modo mais eficiente de produzir bens e serviços para a sociedade industrial. Williamson (1985, p.16) ressalta que "o caráter de mudança da organização econômica concentra-se entre mercados e hierarquias", e embora reconheça que há deformações nesta relação, acredita que resulta em um sistema econômico mais eficiente, sendo a eficiência entendida através das formas organizacionais, não das práticas concretas. Ela é produto basicamente de quatro elementos: incerteza, negociação em situações de poucos participantes, racionalidade limitada e oportunismo. 
Embora tenha constituído um avanço no sentido de encarar a realidade em termos de seu relacionamento com o ambiente (numa base estruturada em termos de pressão sobre a organização) e leve em consideração o fato de que há uma base contratual que rege os procedimentos individuais no contexto organizacional (indicando que nem sempre a tão propalada 'coesão grupal' é um fator ativo), as novas perspectivas de análise são passíveis de críticas.

Por um lado, a Teoria da Firma ignora os aspectos cooperativos da sociedade e o fato de que o poder é baseado na exploração social, devido a uma distribuição desigual, além de que a relação de contrato bilateral não é equitativa: em geral o membro mais forte ou poderoso tem a maior influência. Outro ponto é que, por esta teoria, as pequenas empresas simplesmente deixariam de existir, uma vez que só as grandes corporações teriam espaço neste contexto teórico. Além disso, a noção de contrato, por sua vez, considera não apenas que exista uma abundância de empregos, o que justificaria o 'rompimento' do trabalhador com a empresa caso alguma cláusula não lhe parecesse favorável, como que o trabalhador teria domínio do seu próprio trabalho, assim como a liberdade de 'ir e vir' quando the aprouvesse, o que, definitivamente, não corresponde à realidade organizacional. Neste sentido, parece fácil teorizar quando se afasta da realidade do dia a dia da organização; contudo, perde-se em consistência prática pela não-conformidade da teoria com a prática organizacional.

\section{A Teoria da Administração e o contexto - um balanço}

O contexto no qual se encontram inseridas as organizações revela-se cada vez mais como um condicionador da organização; as novas perspectivas implicam uma superação contínua dos padrões vigentes em nome do "ambiente. Luttwak (1996) vê na globalização um fenômeno diferenciador por excelência, pois enriquece os países em fase de industrialização, empobrece a maioria intermediária e aumenta as rendas dos mais ricos, que controlam ou se beneficiam do processo; contudo, há duas dificuldades na reforma do sistema, sendo a primeira a inevitabilidade das tendências de crescimento demográfico e de degradação ambiental, e a segunda o problema da instrumentalidade das reformas propostas do ponto de vista prático".

Kennedy (1993, p. 344) argumenta que "as forças de mudanças enfrentadas pelo mundo podem ser tão profundas, complexas e interativas que exigem nada menos do que a reeducação da humanidade". Ele encara a educação como a compreensão das razões das mudanças globais, de como os outros povos encaram tais mudanças ou das suas similaridades e diferenças. Para ele, as sociedades devem preparar-se para o século XXI por três razões principais, sendo a primeira a competitividade; a segunda, a necessidade de uma postura ativa frente aos desafios demográficos e ambiental; e a terceira, a redução da instabilidade política e seus níveis relacionados de violência e guerra.

A economia mundial, portanto, passa por uma crise estrutural que revela as contradições da economia de mercado, uma vez que as contínuas reduções de pessoal criaram uma força de trabalho que já não pode mais ser reintegrada ao mercado, pois a "ampliação do modo de produção ultrapassou o seu limite de saturação" (KURZ, 1993, p. 11). O discurso neoliberal (que toma o perdedor como produto natural da renovação produtiva), desta maneira, não se aplica ao caso atual, no qual o caráter de perdedor assume um caráter absoluto: os modelos de sucesso neoliberal apenas podem ser caracterizados como pequenas existências em nichos. 
Kurz (1992) ainda discorda do fato de que o desemprego em massa se deve às consequências da intensificação da produtividade do sistema produtivo e ao deslocamento do trabalho industrial para o Terceiro Mundo. Na sua visão, a tendência ao aumento da intensidade do capital desvalorizou há muito tempo a oferta de mão de obra 'barata'. Ele não aprecia a forma de modernidade atual, o que fica evidente quando afirma que "a maior parte da sociedade foi apenas modernizada em sentido negativo, isto é, foram destruídas as estruturas tradicionais sem que alguma coisa nova ocupasse seu lugar" (KURZ, 1992, p. 194).

No nível organizacional, Coelho (1979, p. 11) defende que "as regras que definem a 'racionalidade' de uma decisão emergem das interações entre os participantes", pois são acordos negociados que permitem ao grupo seguir regras adequadas à situação, de forma que concluise que a 'racionalidade' é uma retórica para a elaboração de um relato de justificação. Assim, mesmo que a organização seja um conjunto coerente e consistente de instruções para ações futuras, ainda é possível interpretá-la como um vocabulário para encobrir dificuldades que surgem da própria tentativa de implementá-lo. O estudioso de organizações se vê de certa forma submetido à gramática de teorização coletiva muito reconhecida pela comunidade acadêmica ou profissional, "e seu status dentro dessa comunidade depende amplamente da adesão à gramática comum" (COELHO, 1979, p. 14).

O elevado nível de competição modifica, de certa forma, a ciência, em especial as ciências sociais, pois conforme Wood (1990, p. 19) destaca, o interessante é "não quão pouco de conteúdo das ciências sociais existe, mas como, através de caminhos diversos e indiretos, as idéias derivadas das ciências sociais emergem embaladas em novas formas". Neste sentido, "o pensamento administrativo, assim, como os próprios negócios, está agora altamente competitivo" (CLUTTERBUCK; CRAINER, 1993, p. 245), o que levou à proliferação de "gurus", indivíduos que "têm a capacidade de articular o que uma série de profissionais conhecem intuitivamente e nunca foram capazes de articular" (CLUTTERBUCK; CRAINER, 1993, p. 241).

Wood (1990, p. 13) ressalta que, apesar disso, "a administração permanece uma ocupação sem uma identidade profissional clara; um papel cheio da tensão de harmonizar interesses diferentes dentro (e fora) da moderna organização; e uma carreira cheia de incerteza, riquezas em potencial e status elevado, e possíveis decepções e estagnação"; mas ela merece ser estudada em si mesma como uma força cultural porque pode ajudar a proporcionar insights para o desenvolvimento conceitual e os projetos de investigações empíricas.

Sem uma apreciação completa da variedade de contextos organizacionais, não teremos uma base adequada para a teoria das organizações. Uma preocupação central dos cientistas sociais deve permanecer sendo a diversidade de práticas entre as organizações: o desafio que a nova onda apresenta às ciências sociais é a investigação do simbolismo nas ações administrativas e os seus efeitos sobre o desempenho econômico.

A administração, portanto, encontra-se frente a demandas específicas por modificações em relação à nova natureza do ambiente que envolve as organizações. A gestão, desta forma, precisa deixar de considerar-se como uma espécie de 'invólucro', imune às pressões ambientais. Assim, as práticas em vigor necessitam de revisão de maneira a tanto adequar as organizações ao seu novo contexto - levando, para isso, em consideração conceito de flexibilidade estrutural à risca - quanto modificar o papel da mão de obra, entendida agora como um membro participante e ativo das mudanças da organização.

Contudo, ao mesmo tempo em que se exige mais da força de trabalho, de forma mais criativa e mais produtiva, sua presença é cada vez mais volátil, principalmente porque se descobriu a palavra "conjuntura", que passou a designar todas as espécies de intempéries a que pode estar sujeita a organização, e esta basta para justificar reduções maciças de pessoal. Esta 
ambiguidade nas relações de trabalho é um fator frequentemente minimizado nas discussões sobre o assunto, mas, certamente, constitui o cerne paradoxal do novo contexto e precisa ser considerado pelas organizações, sob pena de desaparecimento frente à nova e competitiva realidade.

\section{Referências bibliográficas}

BENDIX, R.; FISHER, L. H. As perspectivas de Elton Mayo. In: ETZIONI, A. (Org.). Organizações complexas. São Paulo: Atlas, 1991.

BERTALANFFY, L. V. Teoria geral dos sistemas. Petrópolis: Vozes, 1972.

BEYNON, H. Trabalhando para a Ford. São Paulo: Paz e Terra, 1995.

CARNEIRO, A. M. M. Teorias organizacionais: do ceticismo à consciência crítica. Revista de Administração Pública, Rio de Janeiro, v.29, p.5170, abr./jun. 1995.

CHANDLER, A. Scale and scope: the dynamics of industrial capitalism. Boston: Harvard University Press, 1990.

CHANDLER, A. D. Strategy and structure. Massachusetts: M.I.T. Press, 1976.

CHOMSKI, N. O lucro ou as pessoas. Rio de Janeiro: Bertrand Brasil, 2002.

CHURCHMAN, C. W. Introdução à teoria dos sistemas. São Paulo: Cultrix, 1971.

CLUTTERBUCK, D.; CRAINER, S. Grandes administradores. Rio de Janeiro: Zahar, 1993.

COELHO, E. C. A retórica da racionalidade e o mito da estrutura. Rio de Janeiro: IUPERJ, 1979 (mimeo).

COMTE, A. Curso de filosofia positiva. São Paulo: Abril Cultural, 1978.

DEMO, P. Metodologia científica em ciências sociais. São Paulo: Atlas, 1987.
ETZIONI, A. Organizações modernas. São Paulo: Pioneira, 1967.

FAYOL, H. Administração geral e industrial. São Paulo: Atlas, 1990.

FISCHER, T. M. D. A difusão do conhecimento sobre organizações e gestão no Brasil: seis propostas de ensino para o decênio 2000/2010. Revista de Administração Contemporânea, Curitiba, v.5, p.123-139, Edição Especial, 2001.

FORRESTER, V. Uma estranha ditadura. São Paulo: UNESP, 2001.

FORRESTER, V. O horror econômico. São Paulo: UNESP, 1997.

FOURNIER, V; GREY, C. At the critical moment: conditions and prospects for critical management studies. Human Relations, London, v. 53, n.1, p.7$32,2000$.

GUERREIRO RAMOS, A. A nova ciência das organizações. Rio de Janeiro: FGV, 1981.

GUERREIRO RAMOS, A. Administração e contexto brasileiro. Rio de Janeiro: FGV, 1983.

KATZ, D.; KAHN, R. L. Psicologia social das organizações. São Paulo: Atlas, 1976.

KENNEDY, P. Preparando para o século XXI. Rio de Janeiro: Campus, 1993.

KURZ, R. As luzes do mercado se apagam: as falsas promessas do neoliberalismo ao término de um século em crise. Estudos Avançados, São Paulo, v.7, n.18, p.7-41, maio/ago. 1993.

KURZ, R. O colapso da modernização. São Paulo: Paz e Terra, 1992.

LAWRENCE, P. R.; LORSCH, J. W. As empresas e o ambiente. Petrópolis: Vozes, 1973.

LIMA, M. E. A. O significado do trabalho humano. In CARVALHO, A. O. (Org.). Administração contemporânea: algumas reflexões. Belo Horizonte: Ed. da UFMG, 1988.

LUTTWAK, E. O capitalismo turbinado e suas consequências. Novos Estudos, São Paulo, n.45, jul. 1996. 
MAYO, E. Problemas humanos de una civilización industrial. Buenos Aires: Galatea, 1959.

MERTON, R. K. Sociologia: teoria e estrutura. São Paulo: Mestre Jou, 1968.

MOUZELIS, N. Organización y burocracia. Barcelona: Península, 1975.

PERROW, C. Análise organizacional: um enfoque sociológico. São Paulo: Atlas, 1972.

PERROW, C. Sociologia de las organizaciones. Madrid: McGraw-Hill, 1991.

PRESTES MOTTA, F. C.; BRESSER PEREIRA, L. C. Introdução à organização burocrática. São Paulo: Brasiliense, 1984.

SARAIVA, L. A. S.; PROVINCIALI, V. L. N. Desdobramentos do taylorismo no setor têxtil: um caso, várias reflexões. Caderno de Pesquisas em Administração, São Paulo, v.9, n.1, p.19-33, jan./ mar. 2002.

SARAIVA, L. A. S.; SILVEIRA, L. G. A. Representações sociais do trabalho entre profissionais de um hospital de Minas Gerais. Revista de Gestão USP, São Paulo, v.14, n.2, p.77-91, abr./jun. 2007.

SIMON, H. Comportamento Administrativo. Rio de Janeiro: FGV, 1965.

SLOAN, A. P. Minha vida na General Motors. Rio de Janeiro: Record, 1965.

TAYLOR, F. W. Princípios de administração científica. São Paulo: Atlas, 1990.

WEBER, M. Ensaios de sociologia. Rio de Janeiro: Guanabara, 1982.

WILLIAMSON, O. The economic institutions of capitalism. London: Free Press, 1985.

WOOD, S. J. Buscando a renovação: a nova onda administrativa. Revista de Administração de Empresas, São Paulo, v.30, n.4, p.5-21, out./dez. 1990.

WOODWARD, J. Organização industrial: teoria e prática. São Paulo: Atlas, 1977. 